\title{
Paper-Based Carbon Dioxide Sensors: Past, Present, and Future Perspectives
}

\author{
Manasa Chandramouli 1(D), Vinay Karekura Boraiah 2(D), Rajendra Prasad Shivalingappa ${ }^{3(\mathbb{D})}$, \\ Vrushabendra Basavanna ${ }^{1}$ (D), Shridevi Doddamani ${ }^{4}$ (D), Srikantamurthy Ningaiah 1,* (D) \\ 1 Department of Chemistry, Vidyavardhaka College of Engineering, Visvesvaraya Technological University, Mysuru-570 \\ 002, Karnataka, India \\ 2 Department of Mechanical Engineering, Vidyavardhaka College of Engineering, Visvesvaraya Technological University, \\ Mysuru-570002, Karnataka, India \\ 3 PG Department of Chemistry, Davangere University, Shivagangothri, Davangere-577007, Karnataka, India \\ 4 Chemical Sciences and Technology Division, CSIR-NIIST, Thiruvananthapuram-695 019, Kerala, India \\ * Correspondence: srijmn@vvce.ac.in (S.N.);
}

Scopus Author ID 55786395000

Received: 9.05.2021; Revised: 8.06.2021; Accepted: 10.06.2021; Published: 18.06.2021

\begin{abstract}
Paper-based sensors are a new possible technology for fabricating easy, economical, portable, and expendable analytical devices for various application fields counting, diagnosis clinically, control of the quality of the food, and environmental monitoring. The distinctive characteristics of paper that enable the transport of the passive liquid and the affinity with chemicals/biochemical is the principal lead of employing paper as a sensing platform. Even if paper-based sensors are extremely favorable, they are quite abided due to undeniable constraints, namely, accuracy and sensitivity. Nevertheless, it is forecasted that in the coming times, with improvisation in the fabrication and analytical techniques, that there will be adding new and novel evolution in paper-based sensors. These sensors can meet the present-day intentions of being a cost-efficient and portable device besides contributing high sensitivity and selectivity and multiple analytes biasing. The present work is a review of paper-based sensors for sensing carbon dioxide.
\end{abstract}

Keywords: paper-based sensors; carbon dioxide; food packing.

(C) 2021 by the authors. This article is an open-access article distributed under the terms and conditions of the Creative Commons Attribution (CC BY) license (https://creativecommons.org/licenses/by/4.0/).

\section{Introduction}

In recent times, the call for the safety and quality of the packed foods according to the proclivity of the buyer has awakened the technology to progress new, original, and interestingly inventive techniques in food packaging [1]. Among the different techniques, and based on the ideal condition of the shelf life, the intelligent or smart technology has evolved to be costefficient, versatile, and quick compared with the age-old analytical procedures employed in the food control section [2]. This technique ensures the food quality by continuous monitoring with the transmission of the details through the critical points all along the distribution chain [3].

Production of the byproducts can also be a clear indication for food spoilage, and possibly these can be adapted to detect the quality of the food product. Because of the production and accumulation of the byproducts, under normal atmospheric conditions, the packed food is spoilt [4]. Apart from the byproducts [5], it might also occur due to the acid [6], heat [7] and pressure [8] that is produced within the package. Interestingly, the detector to detect the food spoilage in the packed food should be the one, which can be used for many food 
products without any requirement of the extra advancement in the technology or being dependent upon the type of the food [9]. The heat factor is practically not possible as the amount of heat varies in the stage of deterioration, $\mathrm{pH}$ is not the sign as it varies with different foods, and detection of pressure is also impossible to come into action. Thus the levels of carbon dioxide can be the prime indicator. The carbon dioxide levels are maintained at optimal levels during Modified Atmospheric Packing (MAP) [10]. And therefore, the carbon dioxide sensors employed in the packed foods can directly help detect the food's quality from packing until it reaches the consumer [11]. Though there are plenty of advancements in developing the carbon dioxide sensors, it has been a fall down in the food packaging industry due to huge energy requirement, bulkiness, expensiveness, and may also be related to certain safety concerns [12]. It can be summed up as the carbon dioxide sensors are not versatile in the food packing industry [13]. Thus an efficient sensor that can sense the gas levels appropriately can come as a successful invention, barring all the limitations of the existing sensors [14]. These carbon dioxide sensors are ruling over the recent times in the food and agricultural industry as a channelized way for assessing food safety because assessing the levels of carbon dioxide in stored or packed foods is a clear indication of the quality of the food [15]. The development of an inexpensive sensor for carbon dioxide of great potential for reliable results is trolling over as the buyer is in the era driven for food safety and quality [16]. The collection of data is important to design and develop a process. This has demanded a dependency on sensor technology. It plays a pivotal role in decision-making at real times for being reliable. It has to take up the challenge of being unique and good on par with the traditional industrial sensors in terms of different parameters and the working environment. They should be borne with the capacity of handling the versatility over variable foods. The interpretation of the data computed by the sensor should have easy predictability from the users. Since carbon dioxide is being used in MAP to a wide range, the decrease in its levels can prove the safety and quality of the packed foods. Hence, this shows the extreme necessity of carbon dioxide sensors for various sectors in the food industry [17].

\section{The Passing Trends}

In the current review, advancements in the growth of various types of $\mathrm{CO} 2$ sensors, namely optical sensors, polymer opal films, polymer hydrogels, paper-based, etc., which can be promptly relevant in applications such as food packaging, have been considered.

The advancement in various fields has initiated paper-based assay technology. A wide recognition has been there for the PADs or paper-based sensors in the research industry. It is also correlated with academics. It also accounts for a low-cost product which is of great interest. It is added with advantages [18] as it has simple fabrication [19] and high speed [20] of analysis. The easy adaptability [21] and their versatility [22] have made them more popular and also have been recognized as an easy analytical tool [23]. This has paved the way for the assessment of small and large productions [24] characterized for a screening technique [25] that is portable [26] and also accountable with the point of care (POC) [27]. A copious source that is available as weightless, [28] of various thickness, [29] biodegradable [30] proving the environmental compatibility [31] are the properties accorded with paper [32]. It has been a good platform in a natural way to incorporate the channels with micro fluids [33] as it can be easily coated, printed, and also be infused by biomolecules and chemical reagents [34] and thus can be transformed as a cost-effective diagnostic portable tool [35] due to its hydrophilic nature and porous behavior. 
There is a rise in the new era of analytical chemistry in engineering paper sensors. Microfluidic paper-based analytical devices ( $\mu$ PADs) (Figure 1) efficiently diagnose the POC with high sensitivity and is multi-functional. There is an increase in the fabrication of these $\mu$ PADs as per the market needs.

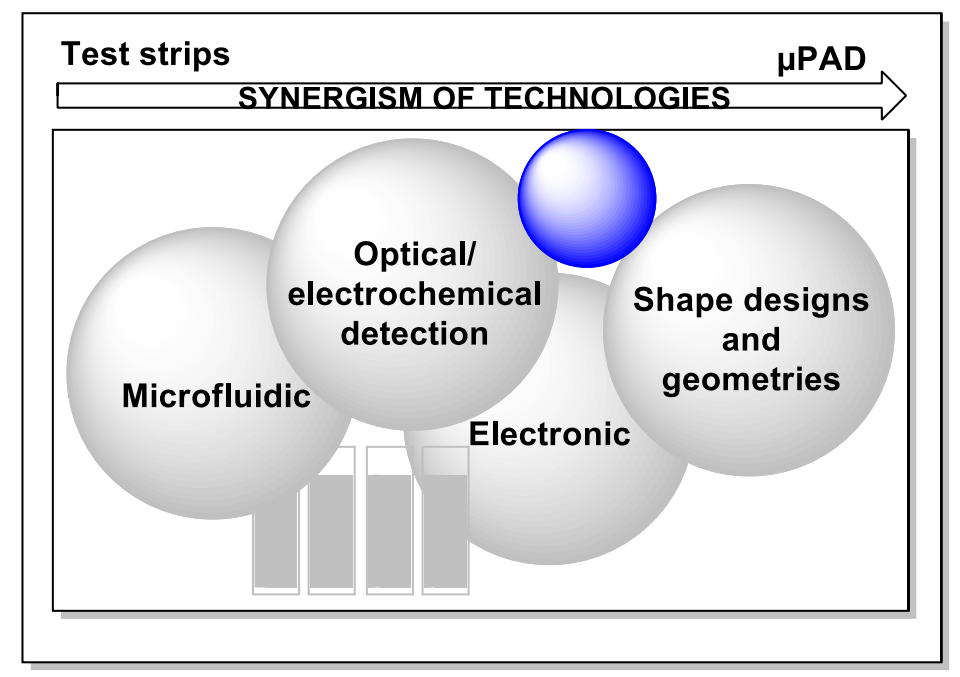

Figure 1. Schematic representation of $\mu \mathrm{PAD}$ used for $\mathrm{CO}_{2}$ analysis.

Yet, an integrated gadget is demanded, which can constitute all the relevant stages of analysis. The gradual increase in the production of the $\mu$ PADs depends on the global needs, the area to which it has to be applied, the design trends, technology that can be newly invented. It is necessary to comprehend the possibilities that can improve the versatility and its necessity to produce more in the case of $\mu \mathrm{PAD}$ technology. And, thus enhancing the manufacture and marketing of $\mu$ PADs [36].

A sensor is developed for easy handling incorporated with high reliability to show stability at various working environments with different atmospheric pressure levels. The interconnected transducers are coated with amino group-functionalized silica nanoparticles that react with the carbon dioxide backing an acid-base reaction in Ormocer sensing material (Figure 2). These sensors exhibit reproducibility and fine selectivity in monitoring carbon dioxide. The reaction between amino-functionalized silica nanoparticles and carbon dioxide is reversible and a fast reaction. Thus the sensor is advantageous in taking quick results. This kind of sensor can detect carbon dioxide levels from 400 to $2000 \mathrm{ppm}$ at a temperature of about $60^{\circ} \mathrm{C}$ through amine-functionalized nanoparticles. These sensors are not sensitive to other gases, namely acetone [37].

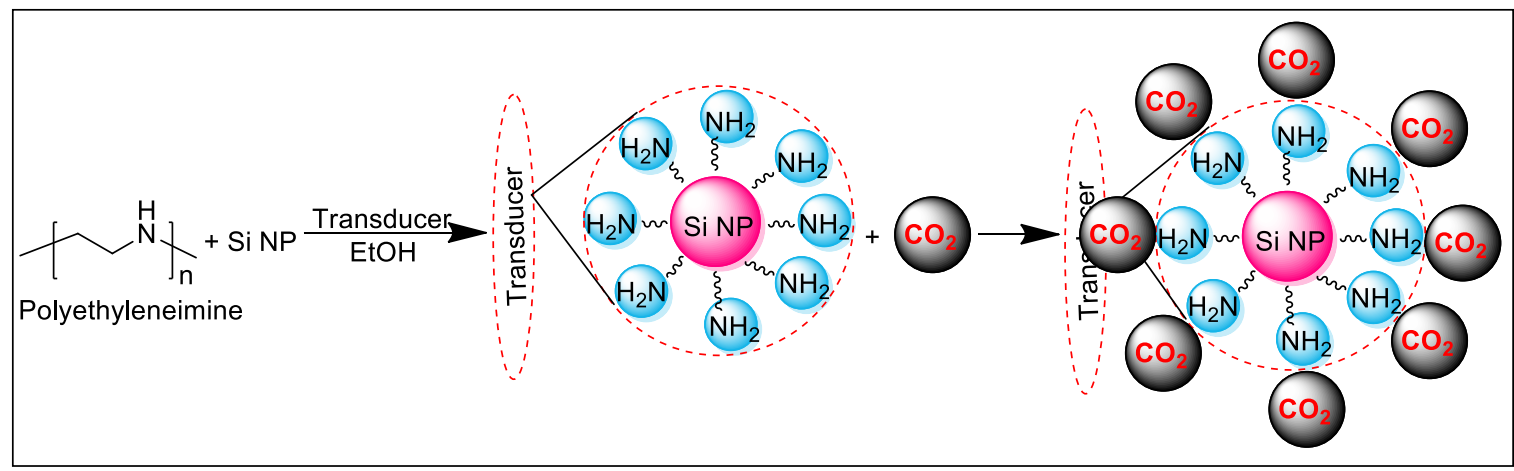

Figure 2. Schematic representation of $\mathrm{CO}_{2}$ sensing by NH3-functionalized silica nanoparticles.

Polyaniline $\mathrm{CO}_{2}$ sensors (Figure 3) are studied as a polymer film in the sensor, which adsorbs carbon dioxide and water. It plays a major role in polyaniline $\mathrm{CO}_{2}$ sensors. It is a sensor 
that works at fixed temperatures, and pressure has been noted. The loading number can be increased by increasing the polymer-analyte interaction. The working range is around $10^{2}, 10^{4}$ ppm, making it applicable for carbon dioxide sensing in the agricultural industry. Thus sodium polyaniline salt (NaSPANI) has been proved to be an efficient candidate in sensing carbon dioxide levels in the agricultural field [38].

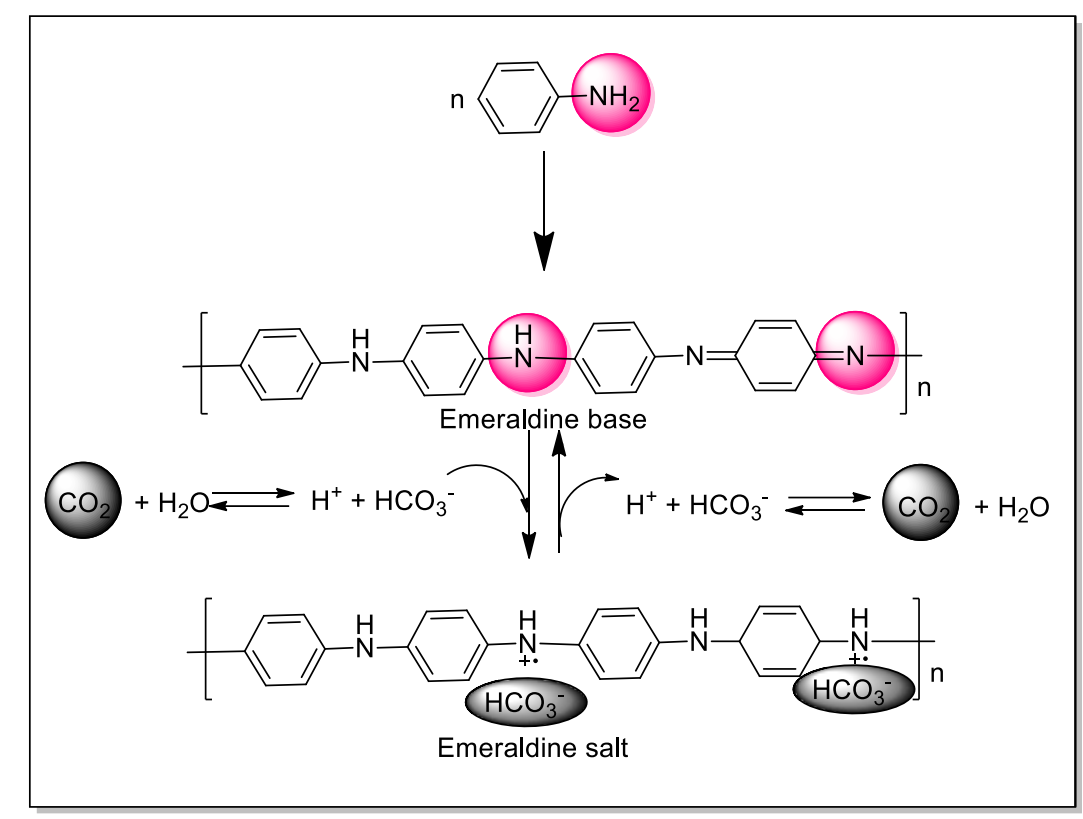

Figure 3. Schematic representation of $\mathrm{CO}_{2}$ sensing by NaSPANI film sensor.

An easy and efficient way of a paper-based sensor using a hydrophobic silicone water repellent spray (Figure 4). This paper-based sensing can be applied for both biological and chemical sensing. The sensing is discussed for carbon dioxide. The performance is selective based on the sensing of dissolved carbon dioxide at different levels of its concentration. This paper-based platform is restricted to only RGB read out from the scanned images, which MATLAB will analyze. Images for carbon dioxide and ammonia will be differentiated by applying the principal component analysis. This paper sensor that has used less expensive readouts driving from the electronic gadgets used by the consumers and with normal lab facilities has been proved to have great potential to work in the real world by showing its applications [39].

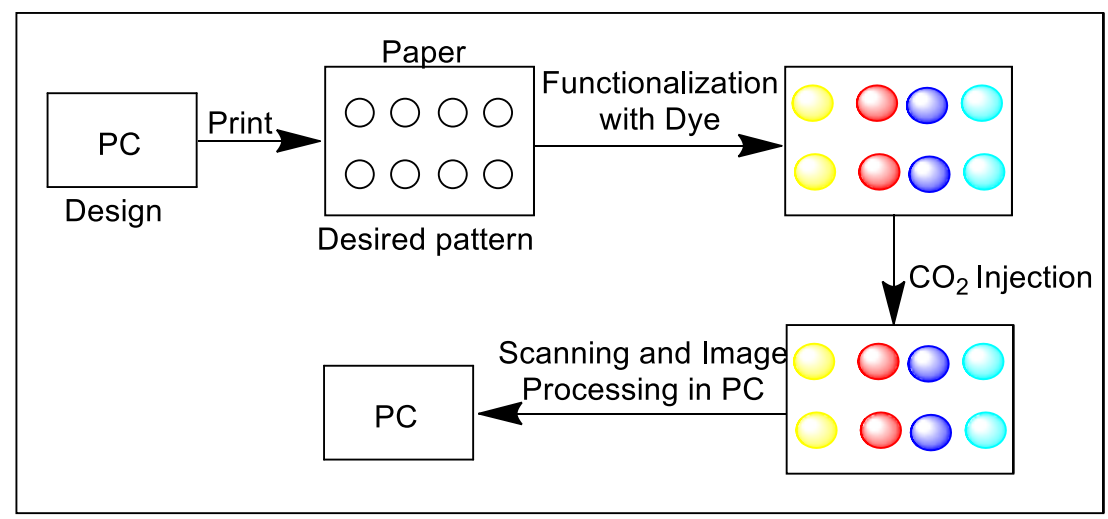

Figure 4. Schematic representation of $\mathrm{CO}_{2}$ sensing by hydrophobic Si-water repellent spray.

A simple fluorescence paper with P4VB infused results in a sensor (Figure 5) which is of low cost and has a response time of about 1 minute. It is more efficient when compared to the other fluorescent paper-based sensors, which also work with the multi-component of the 
atmosphere gases only if there are no acidic gases present in the mixture. It provides a universal design as it can be used wherever there is a requirement for continuous carbon dioxide monitoring in the background, but at the same time, there are limitations for its provisions under uncontrolled atmospheric conditions [40].

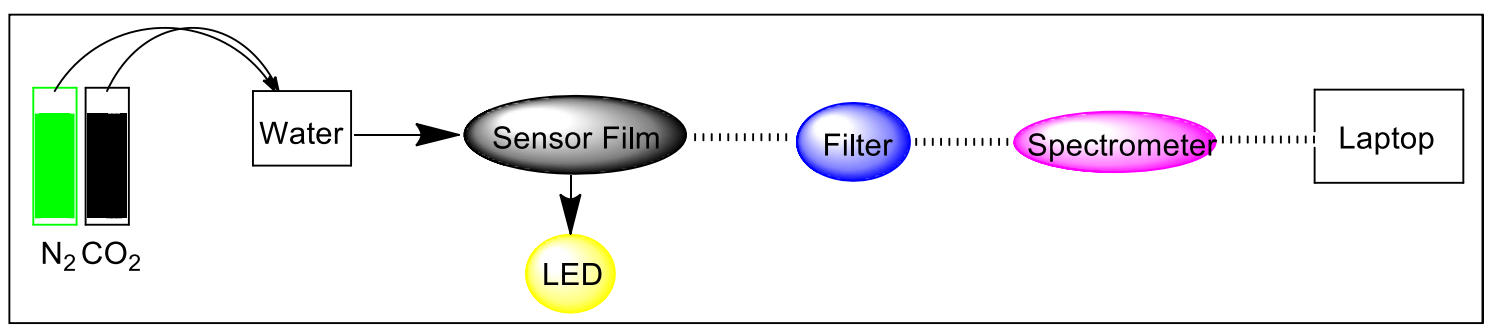

Figure 5. Schematic representation of miniature spectrometer used for real-time $\mathrm{CO}_{2}$ analysis.

A film in which a copolymer is associated with luminescence $\mathrm{pH}$-sensitive dye and is bonded covalently in the presence of tetraocylammonium hydroxide (Figure 6) is presented. This film recognizes the percentage of carbon dioxide in lower levels in both gases and aqueous phases. The advantages added are, firstly, it is not affected by the degree of concentrations of oxygen and carbon monoxide, and secondly, it also exhibits minimum aggregation, and there is no evidence of the leaching of the optical dye. The only disadvantage that has been noted is that any concentration of nitrogen dioxide which is higher than $1 \mathrm{ppm}$ can interfere in the determination of carbon dioxide. Because of this applicability, an optical sensor has been developed, which shows a good range of detection in the gaseous phase [41].

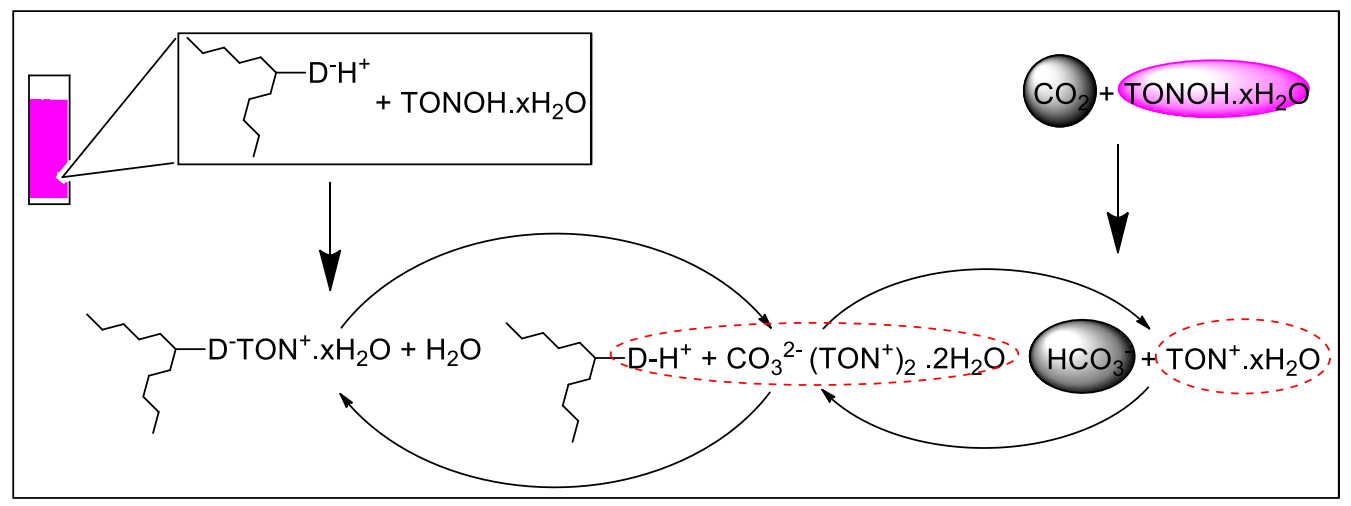

Figure 6. Schematic representation of $\mathrm{CO}_{2}$ sensing by luminescence $\mathrm{pH}$-sensitive dye.

Following the above reviews on paper-based sensors, it can be highly said that there is a huge progress observed in the last few years and it is these works have led to the smarter paper-based sensors. This has also been evident that the future of these smarter paper-based sensors will be a growing field in the area of research. The amalgamation of functional materials over the surface related to being fabrication techniques has to be considered to overrule the limitations that the scripted over, for the generation of a new better and as well as stable devices that can be able to measure many of the analytes at a single sign producing sensitivity at high levels. It is highly relevant to retain the benefits of the paper-based sensors to achieve the necessities of these devices under all conditions, keeping it simple and costefficient [42].

\section{The Future Perspective}

Before these paper-based sensors are commercialized or marketing it is important to address the limitations of the paper-based sensors. There is always a question that is post 
regarding the sensitivity of the analytes [43] and the accuracy that has been reduced because of paper-based sensors, and by removing these drawbacks, the stated sensors can also be counted for precise prognosis in the medical field. Before producing these paper-based sensors in mass, the devices should be compiled for the efficiency of their production, as many of these devices in today's date require a more tough manufacturing procedure [44] which has to be simplified before they get into the market. The price of the devices mentioned above has to be efficiently economical as that it may cause an influence on the usage of the environmental resources.

The point of care devices, which has been inexpensive though with many limitations, does not only serve to be important in the area, namely monitoring the quality of the food or in giving new approaches in the agricultural industry but also have become a key technology in the biomedical research [45] arena involving micro fluids. These portable devices have been very helpful in detecting and diagnosing the biomarkers related to several disorders that of the liver, kidney, and that which is related to diabetes. This paper-based sensor has again proved itself to be an efficient tool in monitoring the toxins and the heavy metals present in many of the contaminated environmental samples.

\section{Conclusions}

The paper-based sensors have proved to be economically viable but have no pieces of evidence of their irreversibility, showing their detection capacity both in closed and open doors. If advanced, the fabrication techniques may end up in a chemistry route by developing visual color-changing sensors based on paper at all ranges of temperature and other atmospheric conditions showing a rapid response on par with that of the available commercially available electrical sensors.

\section{Funding}

This research received no external funding.

\section{Acknowledgments}

The authors are grateful to the Management, Vidyavardhaka College of Engineering, Mysuru, for providing the necessary facility to carry out the research work.

\section{Conflicts of Interest}

The authors declare no conflict of interest.

\section{References}

1. Chen, S.; Sandrayee, B.; Jonathon, M.; Changyong, C.; Bahar, A. The role of smart packaging system in food supply chain. J. Food Sci. 2020, 3, 517-525, https://doi.org/10.1111/1750-3841.15046.

2. Valentine, C.J.; Kensuke, T.; Shinjiro, U.; Ronan, D.; Michael De, V. Paper based electrochemical sensors using paper as scaffold to create porous carbon nanotube electrodes. ACS Appl. Mater. Interfaces 2020, 12, 30680-30685, https://doi.org/10.1021/acsami.0c04896.

3. Yousefi, H.; Hsuan-Ming, S.; Sara, M. I.; Kais, A.; Carlos D. M. F.; Tohid, F. D. Intelligent food packaging: A review of smart sensing technologies for monitoring food quality. ACS Sens. 2019, 4, 808-821, https://doi.org/10.1021/acssensors.9b00440. 
4. Saliu, F.; Roberto, D.P. Carbon dioxide colorimetric indicators for food packaging application: Applicability of anthocyanin and poly-lysine mixtures. Sensor Actuators B:Chemical 2018, 1117-1124, https://doi.org/10.1016/j.snb.2017.12.007.

5. Faustino, M.; Veiga, M.; Sousa, P.; Costa, E.M.; Silva, S.; Pintado, M. Agro-food byproducts as a new source of natural food additives. Molecules. 2019, 24, 1056, https://dx.doi.org/10.3390\%2Fmolecules24061056.

6. Odeyemi, O.A.; Alegbeleye, O.O.; Strateva, M.; Stratev, D. Understanding spoilage microbial community and spoilage mechanisms in foods of animal origin. Compr. Rev. food sci.f. 2020, 19, 311-31, https://doi.org/10.1111/1541-4337.12526.

7. $\quad$ van den Brule, T.; Lee, C.L.; Houbraken, J.; Haas, P.J.; Wösten, H.; Dijksterhuis, J. Conidial heat resistance of various strains of the food spoilage fungus Paecilomyces variotii correlates with mean spore size, spore shape and size distribution. Food Res. Int. 2020, 1, 109514, https://doi.org/10.1016/j.foodres.2020.109514.

8. Buerman, E.C.; Worobo, R.W.; Padilla-Zakour, O.I. High pressure processing of spoilage fungi as affected by water activity in a diluted apple juice concentrate. Food Control. 2020, 1, 106779, https://doi.org/10.1016/j.foodcont.2019.106779.

9. Soleimani, E.; Aghamiri, S.F.; Molla-Abbasi, P.; Shabanian, M. Tuning the polymer-graphene interfaces by picric acid molecules to improve the sensitivity of a prepared conductive polymer composite gas detector. Iran. Polym. J. 2020, 29, 341-350, https://doi.org/10.1016/j.foodchem.2019.125908.

10. Fan, K.; Zhang, M.; Jiang, F. Ultrasound treatment to modified atmospheric packaged fresh-cut cucumber: influence on microbial inhibition and storage quality. Ultrason. Sonochem. 2019, 1, 162-170, https://doi.org/10.1016/j.ultsonch.2019.02.003.

11. He, S.; Yuan, Y.; Nag, A.; Feng, S.; Afsarimanesh, N.; Han, T.; Mukhopadhyay, S.C.; Organ, D.R. A review on the use of impedimetric sensors for the inspection of food quality. Int. J. Env. Res. Pub. He. 2020, 17, 5220, https://doi.org/10.3390/ijerph17145220.

12. Lim, H.R.; Kim, H.S.; Qazi, R.; Kwon, Y.T.; Jeong, J.W.; Yeo, W.H. Advanced soft materials, sensor integrations, and applications of wearable flexible hybrid electronics in healthcare, energy, and environment. Adv. Mater. 2020, 32, 1901924, https://doi.org/10.1002/adma.201901924.

13. Puligundla, P.; Junho, J.; Sanghoon, K. Carbon dioxide sensors for intelligent food packaging applications. Food Control 25 2012, 1, 328-333, https://doi.org/10.1016/j.foodcont.2011.10.043.

14. Lin, Y.; Fan. Z. Compositing strategies to enhance the performance of chemiresistive $\mathrm{CO}_{2}$ gas sensors. Mater. Sci. Semicond. Proc. 2020, 1, 104820, https://doi.org/10.1016/j.mssp.2019.104820.

15. Kaliyan, N.; R. V. Morey; W. F. Wilcke; K. Alagusundaram; P. Gayathri. Applications of carbon dioxide in food and processing industries: current status and future thrusts. ASABE, 2007, 1, https://doi.org/10.13031/2013.23553.

16. Tian, Y.; Deng, P.; Wu, Y.; Liu, J.; Li, J.; Li, G.; He, Q. High sensitive voltammetric sensor for nanomolarity vanillin detection in food samples via manganese dioxide nanowires hybridized electrode. Microchem. J. 2020, 1, 104885, https://doi.org/10.1016/j.microc.2020.104885.

17. Shafiq, M.; Anjum, S.; Hano, C.; Anjum, I.; Abbasi, B.H. An overview of the applications of nanomaterials and nanodevices in the food industry. Foods. 2020, 9, 148, https://doi.org/10.3390/foods9020148.

18. Goryacheva, I.Y.; Lenain, P.; De Saeger, S. Nanosized labels for rapid immunotests. Trends Anal. Chem., 2013, 46, 30-43, https://doi.org/10.1016/j.trac.2013.01.013.

19. Petryayeva, E.; Russ Algar, W. Toward point-of-care diagnostics with consumer electronic devices: the expanding role of nanoparticles. RSC Adv. 2015, 5, 22256-22282, https://doi.org/10.1039/C4RA15036H.

20. Sun, J.; Xianyu, Y.; Jiang, X. Point-of-care biochemical assays using gold nanoparticle-implemented microfluidics. Chem. Soc. Rev. 2014, 43, 6239-6253, https://doi.org/10.1039/C4CS00125G.

21. Yetisen, A.K.; Akram, M.S.; Lowe, C.R. Paper-based microfluidic point-of-care diagnostic devices. Lab on a Chip 2013, 13, 2210-2251, https://doi.org/10.1039/C3LC50169H.

22. Posthuma-Trumpie, G.A.; Korf, J.; van Amerongen, A. Lateral flow (immuno) assay: its strengths, weaknesses, opportunities and threats. A literature survey. Anal. Bioanal. Chem. 2009, 393, 569-582, https://doi.org/10.1007/s00216-008-2287-2.

23. Cate, D.M.; Adkins, J.A.; Mettakoonpitak, J.; Henry, C.S. Recent Developments in Paper-Based Microfluidic Devices. Anal. Chem. 2015, 87, 19-41, https://doi.org/10.1021/ac503968p.

24. Ngom, B.; Guo, Y.; Wang, X.; Bi, D. Development and application of lateral flow test strip technology for detection of infectious agents and chemical contaminants: a review. Anal. Bioanal. Chem. 2010, 397, 11131135, https://dx.doi.org/10.1007/s00216-016-9531-y. 
25. Liana, D.D.; Raguse, B.; Gooding, J.J.; Chow, E. Recent Advances in Paper-Based Sensors. Sensors 2012, 12, 11505-11526, https://doi.org/10.3390/s120911505.

26. Ispas, C.R.; Crivat, G.; Andreescu, S. Review: Recent Developments in Enzyme-Based Biosensors for Biomedical Analysis. Anal. Lett. 2012, 45, 168-186, https://doi.org/10.1080/00032719.2011.633188.

27. Nahavandi, S.; Baratchi, S.; Soffe, R.; Tang, S.Y.; Nahavandi, S.; Mitchell, A.; Khoshmanesh, K. Microfluidic platforms for biomarker analysis. Lab Chip 2014, 14, 496-1514, https://doi.org/10.1039/C3LC51124C.

28. Hu, J.; Wang, S.Q.; Wang, L.; Li, F.; Pingguan-Murphy, B.; Lu, T.J.; Xu, F. Advances in paper-based pointof-care diagnostics. Biosens. Bioelectron. 2014, 54, 585-597, https://doi.org/10.1016/j.bios.2013.10.075.

29. Martinez, A.W.; Phillips, S.T.; Whitesides, G.M. Programmable diagnostic devices made from paper and tape. Anal.Chem. 2010, 82, 3-10, https://doi.org/10.1039/C0LC00021C.

30. Bruzewicz, D.A.; Reches, M.; Whitesides, G.M. Low-Cost Printing of Poly(dimethylsiloxane) Barriers To Define Microchannels in Paper. Anal. Chem. 2008, 80, 3387-3392, https://doi.org/10.1021/ac702605a.

31. Maejima, K.; Tomikawa, S.; Suzuki, K.; Citterio, D. Inkjet printing: an integrated and green chemical approach to microfluidic paper-based analytical devices. $R S C A d v$. 2013, 3, 9258-9263, https://doi.org/10.1039/C3RA40828K.

32. Wang, J.; Monton, M.R.N.; Zhang, X.; Filipe, C.D.M.; Pelton, R.; Brennan, J.D. Hydrophobic sol-gel channel patterning strategies for paper-based microfluidics. Lab Chip 2014, 14, 691-695, https://doi.org/10.1039/C3LC51313K.

33. Lu, Y.; Shi, W.; Jiang, L.; Qin, J.; Lin, B. Rapid prototyping of paper-based microfluidics with wax for lowcost, portable bioassay. Electrophoresis 2009, 30, 1497-1500, https://doi.org/10.1002/elps.200800563.

34. Xia, Y.; Si, J.; Li, Z. Fabrication techniques for microfluidic paper-based analytical devices and their applications for biological testing: A review. Biosens. Bioelectron. 2016, 77, 774-789, https://doi.org/10.1016/j.bios.2015.10.032.

35. He, Y.; Wu, Y.; Fu, J.Z.; Wu, W.B. Fabrication of paper-based microfluidic analysis devices: a review. RSC Adv. 2015, 5, 78109-78127, https://doi.org/10.1039/C5RA09188H.

36. López-Marzo.; Adaris, M.; Arben, M. Paper based sensors and assays: a success of the engineering design and the convergence of knowledge areas. Lab Chip 2016, 17, 3150-3176, https://doi.org/10.1039/C6LC00737F.

37. Boudaden, J.; Armin, K.; Hanns-Erik, E.; Ignaz, E. Capacitive $\mathrm{CO}_{2}$ sensor. MDPI 2017, 1, 472. 2017 , https://doi.org/10.3390/proceedings1040472.

38. Chen, X.; Cell, K.Y. W.; Cadmus, A.Y.; Guoqi, Z. Impact of the functional group on the working range of polyaniline as carbon dioxide sensors. Sens. Actuators B Chem 2012, 175, 15-21, https://doi.org/10.1016/j.snb.2011.11.054.

39. Chen, Y.; Yael, Z.; Pooria, M.; Sameer, R. S. Paper based platform for colorimetric sensing of dissolved $\mathrm{NH}_{3}$ and $\mathrm{CO}_{2}$. Biosens. Bioelectron 2015, 67, 477-484, https://doi.org/10.1016/j.bios.2014.09.010.

40. Wang, H.; Sergei, I.V.; Bernhard, R.; Alkiviathes, M. An Ultrasensitive Fluorescent Paper-Based $\mathrm{CO}_{2} \mathrm{Sensor}_{\text {. }}$ ACS Appl. Mater. Interfaces 2020, 18, 20507-20513, https://doi.org/10.1021/acsami.0c03405.

41. Paulina, K.C.G.; Santiago, M.R.; Antonio, L.M.C.; Jorge, F.F.S.; Alberto, F.G. A new highly sensitive and versatile optical sensing film for controlling $\mathrm{CO}_{2}$ in gaseous and aqueous media. Sensor actuat b-chem 2013, 184, 281-287, https://doi.org/10.1016/j.snb.2013.04.074.

42. Nery, E.W.; Lauro, T.K. Sensing approaches on paper-based devices: a review. Anal. Bioanal. Chem. 2013, 405, 7573-7595, https://doi.org/10.1007/s00216-013-6911-4.

43. Gosselin, D.; Belgacem, M.N.; Joyard-Pitiot, B.; Baumlin, J.M.; Navarro, F.; Chaussy, D.; Berthier, J. Lowcost embossed-papermicro-channels for spontaneous capillary flow. Sens. Actuators B 2017, 248, 395-401, https://doi.org/10.1016/j.snb.2017.03.144.

44. Klasner, S.A.; Price, A.K.; Hoeman, K.W.; Wilson, R.S.; Bell, K.J.; Culbertson, C.T. Paper-based microfluidic devices for analysis of clinically relevant analytes present in urine and saliva. Anal. Bioanal. Chem. 2010, 397,1821-1829, https://doi.org/10.1007/s00216-010-3718-4.

45. Singh, A.T.; Darlin, L.; Akhil, M.; Shainlee, T.; Manjot, P.; Gulden C.U. Paper based sensors: emerging themes and applications. Sensors 18 2018, 9, 2838, https://doi.org/10.3390/s18092838. 